\title{
AGUDÍSSIMO: MAQUIAVEL EM ESPINOSA
}

\author{
Extremely acute: Machiavelli in Spinoza
}

\author{
Luiz Carlos Montans Braga

Resumo: No Tratado político, Espinosa, ao primeiro movimento do texto, faz dura crítica àqueles que criaram utopias ao tratarem da política. Tais filosofos, afirma, por tomarem os homens não pelo que são, mas pelo que gostarian que fossem, conceberam uma forma de política que nunca pôde ser posta em aplicaçăo. Tese muito próxima à de Maquiavel, presente em O Príncipe, segundo a qual, para escrever coisa útil neste campo, deve-se ir direto alla verità effettuale della cosa che alla immaginazione di essa. Não casualmente, portanto, no Capítulo V do Tratado politico, último parágrafo, Espinosa usa os termos 'agudíssimo’ e 'prudentíssimo' ao se referir ao florentino. Há mais Maquiavel em Espinosa para além das citações elogiosas? O artigo procurará tratar desta questão ao mostrar alguns traços comuns às respectivas filosofias políticas. Ao que indicam as fontes primárias e alguns comentadores, Espinosa teria se apropriado, e reconceitualizado, à sua maneira, teses-chave do florentino para escrever suas obras, em particular o Tratado político.

Palavras-chave: Maquiavel; Espinosa; Política; interseçôes conceituais.

\begin{abstract}
In the Political Treatise, in the first movement of the text, Spinoza criticizes those who created utopias when dealing with politics. Such philosophers, he asserts, by taking men not for what they are, but for what they would like them to be, conceived a form of politics that could never be put into effect. A thesis very close to that of Machiavelli, present in The Prince, according to which, in order to write something useful in this field, one must go straight alla verita effetuale della cosa che alla immaginazione di essa. Not coincidentally, therefore, in Chapter V, last paragraph, of the Political Treatise, Spinoza uses the terms 'very sharp' and 'prudent' when referring to the Florentine. Is there more Machiavelli in Spinoza beyond the flattering quotations? The article will seek to address this issue by showing some traits common to their respective political phillosophies. As indicated by the primary sources and some commentators, Spinoza would have appropriated, and reconceptualized, in his own way, Florentine key theses to write his works, in particular the Political Treatise
\end{abstract}

Keywords: Machiavelli; Spinoza; Politics; conceptual intersections.

\section{Maquiavel pressuposto}

Laurent Bove, em entrevista concedida a Leon Farhi Neto, afirma acerca da importância de Maquiavel e de suas teses para Espinosa:

No que se refere a Maquiavel, o estudo dos seus textos, em relação a Spinoza, deve nos convencer do quanto o filósofo de Amsterdã é maquiaveliano, não apenas em política, como na sua própria metafísica. Com efeito, é como se Spinoza, ao escrever a sua Ética, conduzisse o pensamento de Maquiavel do plano da política e da história ao plano de imanência da sua ontologia dinâmica. Disso decorre o uso que eu faço da noção de estratégia do conatus, segundo uma formulação que é quase um pleonasmo, porque, para mim, o conatus spinozista (e/ou o esforço que cada ser faz para perseverar em seu ser) é essencialmente (ou 
por natureza) estratégico. UJma estratégia paradoxal, sem finalidade nem modelo, senão que, ontologicamente falando, cada ser é sempre tão perfeito quanto pode ser; isso significa que, no seu esforço indefinido de perseverança en seu ser, cada ser adota, a cada instante, a estratégia perfeita em função das necessidades que ele afirma e com as quais se afronta. A potência spinozista é, assim, em si mesma e por ela mesma, estratégica, isto é, maquiaveliana. ${ }^{1}$

Proponho neste texto apontamentos sobre e a partir da hipótese de L. Bove, com a qual estou alinhado. Ela indica, a meu ver com grande grau de acerto, o quanto Maquiavel foi movimentado por Espinosa tanto para as suas teses políticas quanto para as ontológicas.

\section{O tácito e o explícito: Maquiavel no Tratado político}

Pode-se pensar a presença de Maquiavel em Espinosa considerando apenas o elogio explícito, acompanhado de pequenas ressalvas, presente no Tratado político, o qual se apresenta tanto no Capítulo $\mathrm{V}$, parágrafo 7 , momento-chave do Tratado, quanto no início do Capítulo X do livro.

Ou, em vez disso, pode-se pensar a presença tácita de Maquiavel nos textos de Espinosa como mais significativa que os momentos em que cita e elogia o florentino. Mais significativa, leia-se, mais espraiada e constituindo uma espécie de esqueleto conceitual fundante, presente em especial no Tratado político, texto em torno do qual este artigo gravitará com mais ênfase.

Por que o Capítulo V é, como acima afirmado, momento-chave do Tratado? Qual a razão da sua importância? O referido Capítulo fecha o movimento de exposição das teses gerais do tratado. Com efeito, o Político se inicia com uma demolidora crítica às análises utópicas acerca da política, conclamando a uma ida aos homens tais como são, isto é, coisas singulares naturais, bem como afetivos nas sulas relações com os outros e com o mundo. Desconsiderar o que os homens são para fundar a política no que os teóricos gostariam que eles fossem, é o mesmo que flertar com a utopia e com a quimera, afirma Espinosa². A tradição que Espinosa mira nesta passagem é longa, por isso o adjetivo usado após crítica pode ser demolidora. Estão no alvo da tese-flecha espinosana desde Platão, especialmente em A República (séc. IV a.c.), até Tomas Morus e sua Utopia (séc. XVI d.c.), passando por vários autores, escolas, inclusive contemporâneas a ele (Hobbes, por exemplo).

Ora, esta tese não está presente em nenhum outro autor cânone ${ }^{3}$ da história da filosofia, exceto Maquiavel, que em O Príncipe afirma algo muito semelhante: "pareceume mais convincente ir direto à verdade efetiva da coisa do que à imaginação dessa."

\footnotetext{
${ }^{1}$ BOVE, Laurent. "Entrevista com Laurent Bove". Entrevista, trad. e notas de Leon Farhi Neto e Monique Farhi. In: Cadernos Espinosanos. São Paulo: n. 33, jull/dez 2015, pp. 223-246.

2 ESPINOSA. Tratado polííco. Tradução, introdução e notas de Diogo Pires Aurélio. São Paulo: Martins Fontes, 2009, pp. 05-06.

${ }^{3}$ Digo autor cânone pois, segundo Wim Klever, a fonte de Espinosa não seria Maquiavel, mas Van den Enden, que foi professor de Espinosa e, mesmo tendo teses muito próximas às de Espinosa, ficou como autor lateral na história das ideias. Ver: KLEVER, Wim. Imperium aeternum: Spinoza's critique of Machiavelli and its source in Van Den Enden. http:/www.fogliospinoziano.it/articolispinoza/IMPERIUM\%20AETERNUM.PDF. Acesso em 28 ABR 2017. A passagem a seguir deixa clara a tese de Klever. "Se uma coisa é proeminente nas duas publicações clandestinas disponíveis de Van den Enden, trata-se de sua incontestável ênfase na igualdade irrestrita e incondicional dos cidadãos (enquanto tais) e na falta de qualquer forma de doninaçăo de um cidadão (ou mais) sobre os demais como condição necessária de um estado realmente livre. É precisamente a rejeição da possibilidade de um estado livre quando cidadãos têm poder desigual, que faz dele um predecessor de Espinosa na luta pela democracia real, o que inclui, por parte de ambos, uma crítica e seletiva atitude em face de Maquiavel." (p. 07). Ou seja, não caberia no pensamento de ambos a divisão entre grandes e povo proposta por Maquiavel tanto nos Discorsi, quanto em O Príncipe, bem como na História de Florença. Outra passagem atesta a tese de Klever: "Van den Enden manifesta-se neste trabalho como um democrata radical, provavelmente o primeiro entre todos os escritores políticos em nossa filosofia ocidental." (pp. 08-09; p. 13). Sobre Van den Enden como o teórico por trás da filosofia política de Espinosa, em vez de Maquiavel como a principal fonte, conferir: KLEVER, Wim. "A teoria política radical de Van den Enden por trás da teoria política
} 
Ao final do movimento argumentativo cujo início foi o Capítulo I do Político, tem-se o elogio com ressalvas mínimas.

Qual o contexto do uso dos termos prudentíssimo e agudíssimo? E qual o seu sentido, isto é, são apenas passagens que se resumem a elas mesmas, ao local em que estão inseridas, ou há mais Maquiavel em Espinosa, pressuposto e espraiado pela obra?

Neste artigo, analisarei com mais detalhe o Político, deixando para outra ocasião eventual presença de Maquiavel no Tratado Teológico-político e na Ética, assim como nos demais textos e no epistolário.

Voltando ao fio que ficou solto, o do lugar do Capítulo V. Trata-se de Capítulo que prepara o terreno para a análise dos regimes políticos - monarquia, aristocracia, democracia. Quanto a este último tema, Espinosa não o desenvolveu, pois faleceu antes da finalização do Capítulo XI do Tratado político, aquele que contém o início das elaborações sobre a democracia. Quais as condições para o melhor estado (imperium)?

No parágrafo primeiro, Espinosa esboça a tese de que o melhor imperium seria aquele em que os homens se conduzissem maximamente pela razão. Este um ponto que não alongarei aqui, mas a tese espinosana é a de que a razão é o lugar do acordo máximo, por motivos ontológicos. Se todos agissem de acordo com a razão, todos os direitos da cidade seriam respeitados ${ }^{5}$. Esta uma tese que está igualmente na Ética, no momento em que Espinosa afirma que haveria apenas acordo se os homens se conduzissem pela razão ${ }^{6}$. Mas, o fato é que "é raro que os homens vivam sob a conduta da razão." Na maior parte das vezes, "são invejosos e molestos uns aos outros."8

De volta ao Tratado político, Capítulo $\mathrm{V}$. O parágrafo segundo indica um caminho de resposta à questão ao definir um critério: a melhor situação para cada estado se conhece pela finalidade do estado, a saber, a paz e a segurança de vida. Aquele em que os homens passam a vida em concórdia e no qual os direitos se conservam inviolados.9 Desenvolve então o argumento de que os homens se fazem civis. Portanto, todos os males relativos à violação de direitos, segundo Espinosa, podem ser atribuídos à má instituição do estado. E conclui que "um estado civil que não elimina as causas das revoltas, onde há continuamente que recear a guerra e onde, finalmente, as leis são com frequência violadas, não difere muito do próprio estado natural"10.

o parágrafo terceiro afirma a mesma tese, pelo seu outro lado. Assim como o mau comportamento dos súditos deve ser atribuído à má institucionalidade, assim também a virtude, isto é, a observância das leis, deve ser atribuída à boa institucionalidade, aquela que canaliza os afetos para o caminho da concórdia, isto é, paz e securitas.

O parágrafo quarto é o momento em que Espinosa define paz não como ausência de guerra (tese, portanto, contrária à de Hobbes ${ }^{11}$ ), mas como virtude que nasce

de Spinoza". Traduzido do inglês por Nastassja Pugliese. In: BECKER, R.C; FRAGoso, E.A.R.; GUIMARAENS, F.; ITOKAZU, E.M.; ROCHA, M. (orgs.). Spinoza e Nós. Vol. 2 - Spinoza Atual/Inatual Rio de Janeiro: Ed. PUC Rio, 2017, pp. 334-367.

${ }^{4}$ MAQUIAVEL. O Príncipe. Edição bilíngue. Tradução de José Antônio Martins. São Paulo: Hedra, 2011, p. 151. ${ }^{5}$ ESPINOSA. Tratado político. Tradução, introdução e notas de Diogo Pires Aurélio. São Paulo: Martins Fontes, 2009, p. 28.

${ }^{6}$ ESPINOSA. Ética. Tradução do Grupo de Estudos Espinosanos, da FFLCH USP. São Paulo: ed. EDUSP, 2015, p 425.

${ }^{7}$ Ibid. p. 429 .

${ }^{8}$ Ibid. p. 429

${ }^{9}$ ESPINOSA. Tratado político. Tradução, introdução e notas de Diogo Pires Aurélio. São Paulo: Martins Fontes, 2009, p. 44.

${ }^{10}$ Ibid. p. 44

${ }^{11}$ Hobbes define paz com as seguintes palavras: [...] "durante o período em que os homens vivem sem um poder comum capaz de os manter a todos em respeito, eles se encontram naquela condição a que se chama guerra; [ [...] pois a guerra não consiste apenas na batalha, [...] mas naquele lapso de tempo durante o qual a vontade de travar batalha é suficientemente conhecida. [...] a natureza da guerra não consiste na luta real, mas na conhecida disposição para tal, durante todo o tempo em que năo há garantia do contráíio. Todo o tempo restante é de paz." HOBBES. Leviatã ou matéria, forma e poder de um Estado Eclesiástico e Civil Tradução de João Paulo Monteiro e Maria Beatriz Nizza da Silva (Coleção Os Pensadores). São Paulo: Abril Cultural, 1997, p. 109. 
da fortaleza de ânimo. Ou seja, aqui se expõe a tese já presente na Ética de que o que importa é que o conatus (potência de cada coisa singular para perseverar em seu ser) dos hhomens possam se exercer com vistas ao aumento de potência ${ }^{12}$. $E$, por fim, no movimento contrário ao das teses hobbesianas, Espinosa diz que a cidade cuja paz depende da inércia dos súditos não deve se chamar cidade, mas solidão.

Como consequência da tese da paz como fortaleza de ânimo, Espinosa concluí que o melhor estado é aquele em que os homens passam a vida em concórdia, para finalmente definir vida como vida humana, a qual não se compreende apenas pela circulação do sangue, mas pela razão, verdadeira "virtude e vida da mente" ${ }^{13}$. A razão, aqui, não significa que os homens são sempre racionais e esta racionalidade seria aquela necessária para a concórdia na cidade. Como já afirmara, os homens vivem muito mais sob os afetos que sob a razão ${ }^{14}$.É que onde há acordo há uma razão pressuposta, o que Espinosa chama de noções comuns, tema que não desenvolverei. Tal estado, afirmará Espinosa a seguir, não é aquele imposto sobre a multidão, mas aquele que a multidão livre institui. A multidão livre, por sua vez, é aquela que se conduz - como ocorre com todos os homens, passionais que são - mais pelo afeto esperança que pelo afeto medo.

O afeto esperança é uma expressão da alegria, ou seja, afeto que significa aumento de potência de quem o experiencia. Aquela multidão que se conduz pela esperança cultiva a vida. Ora, a vida é conatus, esforço para perseverar no ser, em ato, o qual todo ser singular realiza, entre eles os homens. Os afetos de alegria são transições de potência do desejo (o homem é essencialmente desejo ${ }^{15}$ ) para mais. Mais afeto de alegria, como a esperança, implica mais potência, mais vida, para cada membro da multidão que assim se conduz e para a multidão como um todo. O inverso é verdadeiro, daí que no mesmo parágrafo dirá que a multidão que se conduz pelo afeto medo - o oposto da esperança, e portanto tristeza, diminuição de potência - é subjugada. Não o medo da lei civil adequadamente produzida, que leva à segurança, derivada da esperança, portanto afeto alegre, mas o medo de uma lei ou que não venha da multidão, direta ou indiretamente, ou que seja instituidora exatamente do medo animal, do desespero, não do medo civil, este sim positivo.

O elogio a Maquiavel vem no derradeiro parágrafo, em momento no qual Espinosa trata de uma questão que deriva do parágrafo sexto.

Ao final do parágrafo sexto, escreve:

aquela [multidão livre] procura cultivar a vida, esta [multidão subjugada] procura somente evitar a morte [...]. Assim, o fim do estado de que alguém se apodera por direito de guerra é dominar e ter servos em vez de súditos. E embora entre o estado que é criado pela multidão livire e aquele que é adquirido por direito de guerra, se atendermos genericamente ao direito de cada um, não haja nenhuma diferença essencial, contudo, quer o fim, como já mostramos, quer os meios com os quais cada um deles se deve conservar têm enormes diferenças. ${ }^{16}$

O parágrafo sétimo, no qual Maquiavel aparece explicitamente, trata, assim, da questão derivada seguinte: como deve agir o príncipe que se move unicamente pelo desejo de dominar e com o fim de fundar e manter um estado? Espinosa afirma que Maquiavel mostrou-o desenvolvidamente ${ }^{17}$. E o chama, nesta ocasião, agudíssimo.

${ }^{12}$ ESPINOSA. Ética. Tradução do Grupo de Estudos Espinosanos, da FFLCH USP. São Paulo: ed. EDUSP, 2015, p. 251 .

${ }^{13}$ ESPINOSA. Tratado político. Tradução, introdução e notas de Diogo Pires Aurélio. São Paulo: Martins Fontes, 2009, p. 45.

${ }^{14}$ ESPINOSA. Ética. Tradução do Grupo de Estudos Espinosanos, da FFLCH USP. São Paulo: ed. EDUSP, 2015, p. 429.

${ }^{15}$ ESPINOSA. Ética. Tradução do Grupo de Estudos Espinosanos, da FFLCH USP. São Paulo: ed. EDUSP, 2015, pp. 253-255.

${ }^{16}$ ESPINOSA. Tratado político. Tradução, introdução e notas de Diogo Pires Aurélio. São Paulo: Martins Fontes, 2009 , p. 45.

${ }_{17}^{17}$ Ibid. p. 46. 
Ressalte-se que Espinosa a seguir indica não saber com que fim o agudíssimo Maquiavel o fez. Supõe que este fim seja bom, o que seria próprio de um homem sábio. $\mathbb{E}$ indica o que a ele, Espinosa, parece ter sido este fim, ou seja, mostrar como é inútil remover o tirano quando as causas pelas quais o príncipe é tirano não podem ser removidas.

Mais ao final, expõe outra hipótese, ao dizer que "ele quis talvez mostrar" 18 quanto uma multidão livre deve precaver-se para não confiar sua salvação a apenas um homem. Por fim, chama Maquiavel de "homem prudentíssimo" e elogia "ele ter sido pela liberdade, para cuja defesa também deu conselhos muito salutares. ${ }^{\text {"19 }}$

Ora, minha hipótese, na linha de alguns comentadores, como Vittorio Morfino ${ }^{20} \mathrm{e}$ Laurent $\mathbb{B o v e}^{21}$, é a de que esta passagem apenas indica um ponto talvez menor em face de todo um caminho em que Maquiavel aparece tacitamente a sustentar o texto de Espinosa.

Desse grande novelo de um Maquiavel pressuposto nos Capítulos iniciais do Político ( I a V), como indica Morfino ${ }^{22}$, puxo um fio que desenvolvo a seguir, a saber, o de um campo comum de conceitos-chave de ambos, os quais, se vistos em proximidade, diferem, mas vistos de maior distância, têm muito em comum. Em suma, o comum a Maquiavel e Espinosa, que os comentadores citados dizem ser o caldo maquiaveliano que Espinosa bebeu para forjar seus próprios conceitos, é uma derivação de teses acerca da política não a partir de homens ideais, mas dos homens como são. Nesse ponto não é exagero dizer que há mais Maquiavel na análise não utópica da política proposta no Capítulo I do Tratado político, tema desenvolvido até o Capítulo $V$, que nos momentos do elogio explícito ao florentino. E pode-se até avançar a tese, na linha de Bove, e afirmar que Espinosa usa o tema da força em toda sua política, e em toda sua ontologia, derivando-o de conceitos maquiavelianos, entre eles o de virtù, compreendido como força, virilidade, potência, pelo florentino. De modo mais amplo: derivando-o do materialismo do florentino.

É claro que Maquiavel não possui uma ontologia refinada e desenvolvida, ainda que possua um materialismo pressuposto, talvez bebido em Lucrécio, no Da Natureza das Coisas (De Rerum Natura) ${ }^{23}$. Mas teses-chave, como a da leitura da política pelo que ela é, a concepção da política como campo de forças, os homens como afetivos e o valor altíssimo dos afetos e paixões para as análises de cenários políticos, enfim, todos esses traços estão em ambos e, ao que indicam os textos de Espinosa, este os teria buscado, para os forjar com suas ferramentas, em Maquiavel.

\footnotetext{
${ }^{18}$ Ibid. p. 46.

${ }^{19}$ Tbid. p. 46.

${ }^{20}$ MORFINO, Vittorio. Le Temps et I'Occasion: la rencontre Spinoza-Machiavel. Tradução de Lucile Langlois e Maxime Giglio. Paris: Gamier, 2012.

${ }^{21}$ BOVE, Laurent. "Introduction". In: SPINOZA. Traité Politique. Trad. d'Émile Saisset. Révisée par Laurent Bove. Int. e notes par Laurent Bove. Paris: Librairie Générall Française, 2002, pp. 09-10.

${ }^{22}$ MORFINO, Vittorio. Le Temps et I'Occasion: la rencontre Spinoza-Machiavel. Tradução de Lucile Langlois e Maxime Giglio. Paris: Gamier, 2012, p. 98.

${ }^{23}$ Maquiavel transcreveu o poema filosófico de Lucrécio, De Rerum Natura, que contém teses atomistas e materialistas, de inspiração epicurista, acerca da natureza do real. O manuscrito se encontra na Biblioteca Vaticana. Para esta informação: VALVERDE, Antonio José Romera. "Maquiavel e a origem política dos conceitos políticos modemos". In: Aurora: revista de arte, mídia e política. São Paulo: n. 18, vol. 06, 2014, pp. 8589, p. 86. Acerca da influência do materialismo de Lucrécio na obra do florentino, autor nunca citado por Maquiavel diretamente, afirma Valverde: "Em 1497, transcreveu o longo poema filosófico, De Rerum Natura, de Lucrécio, sob inspiração epicurista, logo naturalista atomista, cuja confirmaçăo e autógrafo săo de 1961, e o original encontra-se depositado na Biblioteca Vaticana. Porém, Maquiavel nunca citou Lucrécio em suas obras. Há sim, de modo latente o porejar do pensamento naturalista lucreciano, como substrato significativo da obra maquiaveliana." (p. 86). Sobre a informação da autoria do manuscrito, cuja confirmação é de 1961, a fonte de Valverde é: GREENBLATT, Stephen. A Virada: o nascimento do mundo moderno. Tradução Caetano W. Galindo. São Paulo: Companhia das Letras, 2012, pp. 186-187. Para a tese da existência, na história da filosofia, de uma corrente subterrânea do materialismo do encontro (o termo é de Althusser), na qual Maquiavel e Espinosa estão na mesma linha cujo início é Epicuro, conferir: ALTHUSSER, Louis. "Le courant souterrain du matérialisme de la rencontre". In: ALTHUSSER, L. Écrits philosophiques et politiques. Tome I. Paris:
} STOCK/IMEC, 1994, pp. 539-579. 


\section{A inspiração maquiaveliana para a ontologia espinosana: uma nota sobre a hipótese}

No Apêndice da parte I da Ética, há ưm excerto em que Espinosa explica com linguagem límpida o que havia demonstrado no correr dos axiomas, definições, proposições e demonstrações acerca do conceito de Deus, ou seja, natureza ou sulbstância. Escreve:

Com isto, expliquei a natureza de Deus e suas propriedades, tais como: que existe necessariamente; que é único; que é e age pela só necessidade de sua natureza; que é causa livre de todas as coisas e como o é; que tudo é em Deus e depende dele de tal maneira que sem ele nada pode ser nem ser concebido; e, finalimente, que tudo foi predeterminado por Deus [quòd omnia à Deo fuerint praedeterminata], não decerto pela liberdade da vontade, ou seja, por absoluto beneplácito, mas pela natureza absoluta de Deus, ou seja, por sua potência infinita. ${ }^{24}$

Esta uma passagem que explicita Deus ou a substância como potência. Pois esta potência definirá, no Tratado político, o conceito de direito natural, do ponto de vista dos homens, como coisas singulares potentes. Isso implica que não há corte entre ontologia e política, mas a política é construída no interior do campo ontológico, pois não há outro (o real é Deus ou a substância em operação imanente). Por este raciocínio, vê-se que L. Bove está em bom caminho ao dizer que Espinosa se apropria de Maquiavel, de seus conceitos, para forjar os seus próprios. Isto é, trata-se de uma linha não utópica de análise da política, como o atesta o Político ${ }^{25}$, e também uma linha materialista cujo início bem pode ter sido o Lucrécio do De Rerum Natura.

Veja-se o excerto do Político:

A partir [...』 daqui [...] entendemos facillmente o que é o direito de natureza. [...】] uima vez que Deus tem direito a tudo e que o direito de Deus não é senão a própria potência de Deus na medida em que se considera esta como absolutamente livre, segue-se daqui que qualquer coisa natural đe os homens são coisas naturais e são modificações de Deus, ou seja, modificações da e na substância] tem por natuireza tanto direito quanta potência para existir e operar tiver, pois a potência de cada coisa natural, pela qual ela existe e opera, não é outra senão a própria potência de Deus [.... $]_{0}^{26}$

Em Maquiavel, por seu turno, tem-se uma ontologia menos desenvolvida, é certo, mas presente e pressuposta em todos os passos dos textos. Tomemos algumas dessas passagens para comprovar a afirmação.

Nos Discorsi, Proêmio do livro I, o florentino defende alguns exemplos do passado como virtuosos para ações do presente. E quanto aos que dizem ser isso inútil, ser tal imitação difícil e impossível, responde: "como se o céu, o sol, os elementos, os homens tivessem mudado de movimento, ordem e poder, distinguindo-se do que eram antigamente."27 Tal tese aparece ainda em outro momento dos Discorsi. "pois os homens - como dissemos em nosso prefácio - nasceram, viveram e morreram, sempre, segundo uma mesma ordenação [con uno medesimo ordine]. ${ }^{\text {"28 }}$ Em outra passagem, afirma que "quem considere as coisas presentes e as antigas verá facilmente que são sempre os

${ }^{24}$ ESPINOSA. Ética. Tradução do Grupo de Estudos Espinosanos, da FFLCH USP. São Paulo: ed. EDUSP, 2015, p. 109.

${ }^{25}$ ESPINOSA. Tratado político. Tradução, introdução e notas de Diogo Pires Aurélio. São Paulo: Martins Fontes, 2009, pp. 05-10.

${ }^{26}$ Ibid. p. 12.

27 MAQUIAVEL. Discursos sobre a primeira década de Tito Lívio. Revisão técnica de Patrícia Fontoura Aranovich. São Paulo: Martins Fontes, 2007, p. 07.

${ }^{28}$ Ibid. p. 52. 
mesmos os desejos e os humores em todas as cidades e em todos os povos, e que eles sempre existiram."29 Igualmente, afirma que "o mundo sempre foi de um mesmo modo, que nele sempre houve o bom e o mau, mas que há variações entre este mau e este bom, de uma província para outra, [...], embora o mundo permanecesse sempre o mesmo."30 Por fim, arremata quase ao final do livro III: "porque todas as coisas do mundo, em todos os tempos, encontram correspondência nos tempos antigos. Isso ocorre porque, tendo sido feitas pelos homens, que têm e sempre tiveram as mesmas paixões, tais coisas só poderão, necessariamente, produzir os mesmos efeitos." ${ }^{\circ 1}$

A pequena ontologia maquiaveliana, sempre pressuposta e usada em seus traçados de cenários políticos, foi bebida por Espinosa e se apresenta ao longo de seus textos. A potência e os afetos estão presentes em ambos, com diferentes nomes e com as nuances próprias a cada autor.

\section{De perto, de longe 4.1 De longe}

Proponho uma metáfora para o exercício de aproximação e distanciamento entre ambos. A depender do grau de aproximação ou distanciamento do painel, tem-se pouco ou muito em comum. Quanto mais distante o observador em face do painel em que os conceitos maquiavelianos e espinosanos estão pintados, maior a semelhança, o que lança águas no moinho dos comentadores que enxergaram uma linha vermelha a unir ambos, a qual derivaria até Marx. Teria seu início em Lucrécio? Talvez em Epicuro, como sugere Althusser ${ }^{32}$, formando a linha do "materialismo do encontro", o qual teria sido sufocado, pois perigoso, ao longo da história da filosofia? Tema para outras pesquisas.

É como se usassem a mesma matéria e a partir dela construíssem os seus próprios conceitos. No caso de Espinosa, apropriando-se de Maquiavel e o usando nas entrelinhas dos seus escritos, porém sempre reformulado, ainda que com grande semelhança de resultados. Como bem resume Saverio Ansaldi, ao analisar a tese de Morfino presente em II tempo e l'occasion ${ }^{33}$, torna-se possível concluir que Espinosa faz uso do pensamento de Maquiavel tanto no Tratado Teológico-político quanto no Tratado político. Há, certamente, continuidade. Nesta chave, Espinosa se cercaria de Maquiavel de uma perspectiva anti-hobbesiana. Há dois momentos que derivam da imersão de Espinosa em Maquiavel, no sentido de aquele, devidamente embebido dos conceitos maquiavelianos, se contrapor a Hobbes. Primeiro, a reversão do jusnaturalismo e do positivismo jurídico hobbesiano feita por Espinosa. Ou seja, Espinosa usa Maquiavel para demarcar sua filosofia em face da de Hobbes ${ }^{34}$. Segundo, e nesse sentido Espinosa igualmente utilizaria Maquiavel, não há descontinuidade entre estado de natureza e estado civil. De fato, o horizonte que constitui o político é constantemente atravessado pela fortuna (ou conjunto causal necessário, porém desconlhecido dos homens como modos finitos, em Espinosa), pelos desejos e pelas paixões da multidão ${ }^{35}$.

Com esta passagem se resume um ponto de contato entre suas filosofias políticas. Mas interessa, igualmente, salientar a ideia presente em ambos, segundo a qual o real é constituído por instâncias de potência, de força, é por elas atravessado. Esse um fundamento que deságua na política em ambos. Por outro lado, há forte presença dos

\footnotetext{
${ }^{29}$ Tbid. p. 121.

${ }^{30}$ Ibid. pp. $178-179$

${ }^{31}$ Tbid. p. 445 .

${ }^{32}$ ALTHUSSER, Louis. "Le courant souterrain du matérialisme de la rencontre". In: ALTHUSSER, L. Écrits philosophiques et politiques. Tome I. Paris : STOCK/IMEC, 1994, pp. 539-579, pp. 539-540.

${ }^{33}$ MORFINO, Vittorio. Le Temps et l'Occasion: la rencontre Spinoza-Machiavel. Tradução de Lucile Langlois e Maxime Giglio. Paris: Gamier, 2012.

${ }^{34}$ Para a distância entre Hobbes e Espinosa, ver: LAZZERI, Christian. Droit, pouvoir et liberté: Spinoza critique de Hobbes. Paris: PUF, 1998. Ver igualmente: MONTANS BRAGA, Luiz Carlos. "A política e os afetos: a concepção espinosana". In: Revista Direito e Práxis. Rio de Janeiro: n. 03, vol. 08, 2017, pp. 2010-2042.

${ }^{35}$ ANSALDI, Saverio. "Conflit, démocratie et multitude: l'enjeu Spinoza-Machiavel". In: Multitudes. Paris: n. 27/4, 2006, pp. 217-225, pp. 220-221. hittps:/Www.cairn.info/revue-multitudes-2006-4-p-217.htm. Acesso em 12 JAN $2018[2006]$
} 
desejos e das paixões como constitutivas dos homens. Isto é, não se faz, nem em Maquiavel, nem em Espinosa, qualquer elaboração de filosofia política sem o terrenobase das instâncias de potências em luta, bem como dos desejos, apetites e paixões como constitutivos dos homens. Eis um pano de fundo comum, ainda que cada qual o elabore à sua maneira.

Ademais, os homens tomam parte nessa trama - moldam e são moldados -, e são essencialmente desejo, que se desdobra nas demais paixões próprias a eles, as quais levam a comportamentos de ação ou de resistência que constituem o campo político. Isto é, estão Maquiavel e Espinosa em chave não formalista e não utópica ${ }^{36}$ de compreensão do político, e o fundamento das construções da política, olhando de razoável distância o painel em que ambos se apresentam, é afetivo.

Espinosa compreende o homem como desejo que varia de mais a menos potência (alegria e tristeza, respectivamente) na duração. No interior desses dois afetos, que são a variação do desejo, essência em ato de cada homem como ser singular, variados outros, deles derivados, se apresentam, como amor e ódio, esperança e medo, segurança e desespero, ambição, inveja, avareza, generosidade, etc. Para Maquiavel, o campo afetivo está na base da construção da política. É certo que há a divisão entre grandes e povo na cidade, mas o que a fundamenta são os humores, ou seja, os apetites em contraste dinâmico entre duas instâncias, uma que deseja mandar e outra que resiste ao mando. Porém, essas aglutinações são fluídas, pois os apetites humanos, esses sempre os mesmos, é que constituem sua natureza, não havendo, senão conjunturalmente, diferenças entre grandes e povo ${ }^{37}$. Ou seja, o povo, que em regra deseja não ser comandado, mas resistir, em outra conjuntura, isto é, um número menor de homens dele derivado - pois os grandes sempre estão em número menor ${ }^{38}$-, pode "mudar de apetite" e passar a desejar o mando. Estes, do povo derivados, já não mais constituem povo, passam a ser parte do rol dos grandes. O fato, entretanto, é que essas aglutinações são fundadas em afetos, e Maquiavel dá fluidez ao campo afetivo, que atravessa seus escritos e os informa a todo momento. Desde a tese de que o governante que angaria o ódio do povo está condenado a perder o poder, até a de que os homens são ambiciosos, rapaces, passando pela dedicação, em O Príncipe, de um capítulo ao tema do amor e do ódio dos governados em face do príncipe ${ }^{39}$, os afetos dão o tom das teses políticas do autor.

Isso, quando se tem o painel a certa distância do olhar. A aproximação, a ida da floresta às árvores, muda o que se enxerga, bem como as conclusões.

\subsection{De perto}

Espinosa deriva o conceito de homem - e sua essência desejante à mercê das afecções que levam a afetos de alegria ou de tristeza, maior ou menor potência - de uma construção ontológica refinadíssima. A ontologia espinosana, presente especialmente nas partes I e III da Ética, deriva para as demais partes (III, IV e V) e aparece como fundamento explícito ou implícito de todas as suas teses políticas, sejam aquelas apontadas na Ética IV, especialmente no escólio 2 da Proposição 37 da parte IV, momento em que traz pinceladas de análise da política ${ }^{40}$, seja no Tratado Teológicopolítico e no Tratado político.

\footnotetext{
${ }^{36}$ ESPINOSA. Tratado político. Tradução, introdução e notas de Diogo Pires Aurélio. São Paulo: Martins Fontes, 2009, pp. 05-06. MAQUIAVEL. O Príncipe. Edição bilíngue. Tradução de José Antônio Martins. São Paulo: ed. Hedra, 2011, pp. 151-153.

${ }^{37}$ MAQUIAVEL. História de Florença. 2a ediçăo. Traduçã̃o, apresentaçằo e notas de Nelson Canabarro. São Paulo: ed. Musa, 1998.

${ }^{38}$ MAQUTAVEL Discursos sobre a primeira década de Tito Lívio. Revisão técnica de Patrícia Fontoura Aranovich. São Paulo: Martins Fontes, 2007, pp. 67-68.

${ }^{39}$ MAQUIAVEL. O Príncipe. Edição billíngue. Tradução de José Antônio Martins. São Paulo: ed. Hedra, 2011, pp. 161-167.

${ }^{40}$ ESPINOSA. Ética. Tradução do Grupo de Estudos Espinosanos, da FFLCH USP. São Paulo: ed. EDUSP, 2015, pp. 435-439.
} 
Em Maquiavel os cenários históricos se sobrepõem consideravelmente a qualquer construção sistemática de uma ontologia. Não há um aprofundamento que se poderia denominar filosófico, no sentido tradicional do termo, ou ao menos aos moldes espinosanos, do tema da ontologia. Porém, um pente fino nos textos extrai uma ontologia presente e demandada nas análises propostas pelo florentino. Maquiavel, não se pode esquecer, está em cenário dos exempla renascentistas, está na geografia conceitual do humanismo cívico florentino, ao mesmo tempo em que rompe por completo com as teses que lhe são anteriores e contemporâneas - com o humanismo cívico florentino igualmente -, como ele mesmo o atesta nos Discorsi, isto é, explicitamente apresenta-se como aquele que trillha o novo ${ }^{41}$. Nesse sentido, como bem lembra Antonio Valverde, as teses de linhagem atomista-materialista, do poema de Lucrécio por ele copiado, De Rerum Natura, cujo talhe é epicurista, porejam na obra maquiaveliana - ainda que ele não faça referência explícita ao autor do poema filosófico ${ }^{42}$.

Em aos menos mais três tópicos a aproximação em face do painel leva a que se veja, no detalhe dos conceitos, as diferenças entre ambos. A primeira, já indicada acima em seus fundamentos, está em que para Espinosa os afetos podem ser alegres ou tristes, constituindo tais conceitos transição de potência, para mais ou para menos, da essência em ato de cada coisa singular humana, aumento ou diminuição de realidade dos homens, uma vez que estes são intensidades finitas da potência infininita da substância. Em Maquiavel esse grau de refinamento - na falta de melhor termo - não existe. Explico o que quero dizer com grau de refinamento. Não que Maquiavel não tenha sutileza. Ele a direciona, entretanto, para a finura na costura da vasta erudição e na análise dos exemplos para deles extrair suas máximas políticas, ou usando sua ontologia menos elaborada para alinhavar os exemplos que trabalha em forma de dípticos que se desdobram em mais e mais dípticos. Ou seja, o modo como Maquiavel faz filosofia política é diverso, por isso a história está muito mais presente na fundamentação, e a ontologia não é tão aprofundada em comparação a Espinosa. Sua filosofia política não tem de início uma preocupação ontológica. Em vez disso, a ontologia esparsa, difusa, porém precisa, ainda que não aprofundada, está a serviço da filosofia política. Esta, por sua vez, está presente em todos os poros da obra do florentino e recheada, à exaustão, de exemplos históricos. Essa uma diferença que se apresenta quando o observador se aproxima do painel em que os conceitos de ambos estão fixados.

Outra diferença que salta aos ollhos é que, ao conceber a divisão fundamental das cidades, entre o humor dos grandes e o do povo, Maquiavel não se preocupa em explicar, de modo sistemático, como se formam esses blocos e por que razão as coisas assim se apresentam. Em Espinosa não há esta divisão, a ontologia que informa o conatus de cada indivíduo humano - ou dos blocos de potência - não os dispõe em instâncias dinâmicas que procuram dominar e resistir e de cujo conflito se dá um de três efeitos (principado, liberdade, licença ${ }^{43}$ ). Há blocos de potência em Espinosa, mas não entre grandes e povo, nobres e plebe, etc., ainda que assim possa ocorrer, como quando ele explica o funcionamento da aristocracia no Tratado Político ${ }^{44}$. Além disso, os blocos de homens em uma cidade se formam no interior do conceito de multidão ${ }^{45}$, que por sua vez demanda o conceito de imitação afetiva para existir como tal. Mesmo os blocos de homens, que operam no interior da multidão, se formam por imitação dos afetos, tema

41 MAQUIAVEL Discursos sobre a primeira década de Tito Lívio. Revisão técnica de Patrícia Fontoura Aranovich. São Paulo: Martins Fontes, 2007, p. 05.

${ }^{42}$ VALVERDE, Antonio José Romera. "Maquiavel e a origem política dos conceitos políticos modemos". In: Aurora: revista de arte, mídia e política. São Paulo: n. 18, vol. 06, 2014, p. 86.

${ }^{43}$ MAQUIAVEL。 O Príncipe. Edição bilíngue. Tradução de José Antônio Martins. São Paulo: ed. Hedra, 2011, p. 103.

${ }^{44}$ ESPINOSA. Tratado político. Tradução, introdução e notas de Diogo Pires Aurélio. São Paulo: Martins Fontes, 2009. Conferir capítulos VIII, IX e X.

${ }^{45}$ Diogo Pires Aurélio conceitua multidão do seguinte modo: "A multidão é um termo charneira [dobradiça], onde se articulam, por um lado, a multiplicidade de desejos ou receios, por outro, a potência comum que se afirma em resultado da sua insustentável dispersão." (AURÉLIO, 2000, p. 275). 
que Espinosa aponta no Tratado político e cujo funcionamento demandou do autor uma minuciosa construção explicitada na Ética, a qual envolve uma série de proposições e demonstrações, tema do qual não tratarei neste artigo ${ }^{46}$. De modo muito resumido, podese dizer que o comportamento dos homens para a fundação e manutenção do estado [imperium] será afetivo, e o mecanismo de imitação dos afetos é que guiará os homens em suas formações no interior da multidão, fundamento da cidade ${ }^{47}$. Apenas para pontuá-lo, Espinosa usa no Tratado político, ao tratar dos blocos de homens e do funcionamento do estado (imperium), o termo "como que por uma só mente [una veluti mente] [...]." 48 Este termo resume todo o desenvolvimento do conceito de imitação afetiva presente na Ética $I I^{49}$ e o demanda para que seja adequadamente compreendido. Ou seja, os homens guiam-se "como que por uma só mente" por meio da imitação do afeto do outro.

No florentino, não há esse rol conceitual, muito menos uma explicação mais desdobrada, analítica, da formação dos grandes e povo e do funcionamento da divisão. Uma relação entre exemplos históricos e ontologia ora explícita, ora implícita, é que dá o tom do texto de Maquiavel ao tratar do tema. A formação conceitual das instâncias poucos/muitos, nobres/plebe, grandes/povo, as quais a todo momento são usadas na filosofia política do florentino, não pode ser buscada além daquela ontologia de que se falou acima, ou seja, homens com mesmas paixões, mesma natureza a operar nos antigos e nos contemporâneos do autor, a constância do movimento de tudo - céu, sol, elementos, homens $s^{50}$ - e a dinâmica encontrada, historicamente, nas cidades, que é a dimensão do conflito entre os poucos e os muitos. Além disso, o que em Espinosa é preocupação com a precisão absoluta dos conceitos, em Maquiavel se esfumaça. Mais preocupado com a precisão das conclusões - eis uma hipótese -, pode-se constatar na obra do florentino certa elasticidade conceitual ou deslize dos termos entre si. Por exemplo, ora usa povo/grandes, ora plebe/nobres, ora muitos/poucos, sem maiores preocupações explicativas quanto à troca dos termos de um lugar para o outro. O mesmo ocorre com os termos desejo, apetite, humores. As análises dos cenários políticos, entretanto, são sempre precisas, não obstante a elasticidade no uso dos termos que fundamentam toda a argumentação.

Pode-se concluir no seguinte sentido. A presença de Maquiavel em Espinosa parece ir além das citações explícitas. Aliás, os momentos em que as citações se apresentam talvez tenham menos Maquiavel que nos movimentos argumentativos, como é o caso do Tratado político nos Capítulos I a V. Há certamente inspiração maquiaveliana em Espinosa, a qual poreja nos textos. Talvez Laurent Bove esteja correto em sua tese mais incisiva: não há apenas citações elogiosas e uso dos conceitos de fundo, maquiavelianos, nas obras políticas. Há algo além, a saber, a presença de uma ontologia do campo de forças que Espinosa bebeu no florentino e transformou na refinadíssima construção ontológica da Ética (Deus é a potência absoluta), a qual, como já afirmado, fundamenta todas as teses políticas de Espinosa (os homens, como modos de Deus, são intensidades de potência).

De volta à metáfora do painel. O olhar a maior distância pode levar a que se veja, entre os conceitos de ambos, grandes semelhanças. O olhar em minúcia, por sua vez,

\footnotetext{
${ }^{46}$ Desenvolvo-o especificamente em: MONTANS BRAGA, Luiz Carlos. Trama afetiva da política: uma leitura da filosofia de Espinosa. Curitiba: ed. Prismas, 2016, pp. 191-227. Autor que trata o tema com grande refinamento é: MATHERON, Alexandre. Individu et communauté chez Spinoza. Paris: Les Éditions de Minuit, 1988, pp. 81 222; pp. 355-446.

${ }_{47}$ MONTANS BRAGA, Luiz Carlos. Trama afetiva da política: uma leitura da filosofia de Espinosa. Curitiba: ed. Prismas, 2016.

${ }^{48}$ ESPINOSA. Tratado político. Tradução, introdução e notas de Diogo Pires Aurélio. São Paulo: Martins Fontes, 2009 , p. $19 ;$ p. 25.

${ }^{49}$ ESPINOSA. Ética. Tradução do Grupo de Estudos Espinosanos, da FFLCH USP. São Paulo: ed. EDUSP, 2015 pp. 279-281.

50 MAQUIAVEL. Discursos sobre a primeira década de Tito Lívio. Revisão técnica de Patrícia Fontoura Aranovich. São Paulo: Martins Fontes, 2007, p. 07.
} 
atesta as diferenças entre as construções teóricas. Tais perspectivas não se excluem, entretanto. Somam-se.

\section{Referências}

ALTHUSSER, Louis. "Le courant souterrain du matérialisme de la rencontre". In: ALTHUSSER, L. Écrits philosophiques et politiques. Tome I. Paris: STOCK/IMEC, 1994, pp. 539-579.

ANSALDI, Saverio. "Conflit, démocratie et multitude: l'enjeu Spinoza-Machiavel". In: Multitudes. Paris: n. 27/4, 2006, pp. 217-225. hhttps://www.caim.info/revue-multitudes2006-4-p-217.htm. Acesso em 12 JAN 2018 [2006].

AURÉLIO, Diogo Pires. Imaginação e Poder: Estudo sobre a Filosofia Política de Espinosa. Lisboa: edições Colibri, 2000.

BOVE, Laurent. "Introduction". In: SPINOZA.Traité Politique. Trad. d'Émile Saisset. Révisée par Laurent Bove. Int. e notes par Laurent Bove. Paris: Librairie Général Française, 2002, pp. 09-10.

BOVE, Laurent. "Entrevista com Laurent Bove". Entrevista, trad. e notas de Leon Farhi Neto e Monique Farhi. In: Cadernos Espinosanos. São Paulo: n. 33, jul/dez 2015, pp. 223246.

ESPINOSA.Spinoza Opera. Ed. de Carl Gebhardt. Heidelberg: Carl Winter, 4 vols, 1972 [1a ed. 1925].

ESPINOSA. Correspondencia. Introducción, traducción, notas e índices de Atilano Domínguez. Madrid: Aliança editorial, 1988.

ESPINOSA. Tratado Teológico-político. Tradução, introdução e notas de Diogo Pires Aurélio. São Paulo: Martins Fontes, 2003.

ESPINOSA. Tratado político. Tradução, introdução e notas de Diogo Pires Aurélio. São Paulo: Martins Fontes, 2009.

ESPINOSA. Ética. Tradução do Grupo de Estudos Espinosanos, da FFLCH USP. São Paulo: ed. EDUSP, 2015.

GREENBLATT, Stephen. A Virada: o nascimento do mundo moderno. Tradução Caetano W. Galindo. São Paulo: Companhia das Letras, 2012.

HOBBES. Leviatã ou matéria, forma e poder de um Estado Eclesiástico e Civil. Tradução de João Paulo Monteiro e Maria Beatriz Nizza da Silva (Coleção Os Pensadores). São Paulo: Abril Cultural, 1997.

KLEVER, Wim. Imperium aeternum: Spinoza's critique of Machiavelli and its source in Van Den Enden. hhttp://www.fogliospinoziano.it/articolispinoza/IMPERIUM\%20AETERNUM.PDF. Acesso em 28 ABR 2017.

KLEVER, Wim. A teoria política radical de Van den Enden por trás da teoria política de Spinoza. Traduzido do inglês por Nastassja Pugliese. In: BECKER, R.C; FRAGOSO, E.A.R。; GUIMARAENS, F。; ITOKAZU, E.M.; ROCHA, M. (orgs.). Spinoza e Nós. Vol. 2 - Spinoza Atual/Inatual. Rio de Janeiro: Ed. PUC-Rio, 2017a, pp. 334-367.

LAZZERI, Christian. Droit, pouvoir et liberté: Spinoza critique de Hobbes. Paris: PUF, 1998.

MACHIAVELLI. Tutte le Opere. A cura de Mario Martelli. Firenze: Sansoni Editori, 1971. 
MAQUIAVEL. História de Florença. 2a edição. Tradução, apresentação e notas de Nelson Canabarro. São Paulo, ed. Musa, 1998.

MAQUIAVEL. Discursos sobre a primeira década de Tito Lívio. Revisão técnica de Patrícia Fontoura Aranovich. São Paulo: Martins Fontes, 2007.

MAQUIAVEL. O Príncipe. Edição bilíngue. Tradução de José Antônio Martins. São Paulo: ed. Hedra, 2011.

MAQUIAVEL。 O Príncipe. Edição bilíngue. Tradução, introdução e notas de Diogo Pires Aurélio. São Paulo: ed. 34, 2017.

MATHERON, Alexandre. Individu et communauté chez Spinoza. Paris: Les Éditions de Minuit, 1988.

MONTANS BRAGA, Luiz Carlos. Trama afetiva da política: uma leitura da filosofia de Espinosa. Curitiba: ed. Prismas, 2016.

MONTANS BRAGA, Luiz Carlos. A política e os afetos: a concepção espinosana. In: Revista Direito e Práxis. Rio de Janeiro: Vol. 08, n. 03, 2017, pp. 2010-2042. http://Www.scielo.br/pdf/rdp/v8n3/2179-8966-rdp-8-3-2010.pdf. Acesso em 11 FEV 2018 [2017].

MORFINO, Vittorio. Le Temps et l'Occasion: la rencontre Spinoza-Machiavel. Tradução de Lucile Langlois e Maxime Giglio. Paris: Garnier, 2012.

VALVERDE, Antonio José Romera. "Maquiavel e a origem política dos conceitos políticos modernos". In: Aurora: revista de arte, mídia e política. São Paulo: V. 6, n. 18, 2014, pp. 8589. 